\title{
Surgical treatment of pulseless pediatric supracondylar humerus fracture ${ }^{2}$
}

\author{
Hamit Serdar Başbuğ * Hakan Göçer, Kanat Özışık \\ Department of Cardiovascular Surgery, Kafkas University Faculty of Medicine, Kars, Turkey
}

\section{A R T I C L E I N F O}

\section{Article history:}

Received 5 March 2017

Accepted 8 May 2017

Available online 8 May 2017

\section{Keywords:}

Pediatric

Humerus fracture

Brachial artery

Injury

\begin{abstract}
A B S T R A C T
Supracondylar humerus fractures in childhood may be accompanied by a vascular injury that is worse than the fracture. The early recognition of the vascular complications is crucial to perform an adequate, and rapid treatment that provides a good prognosis. Early and precise treatment of acute vascular injuries is necessary to avoid a delay which may lead to a permanent disability. In this article, a pediatric case of supracondylar humerus fracture with a brachial artery impairment and the successful surgical treatment is presented.

(C) 2017 The Society of Cardiovascular Academy. Production and hosting by Elsevier B.V. This is an open access article under the CC BY-NC-ND license (http://creativecommons.org/licenses/by-nc-nd/4.0/).
\end{abstract}

\section{Introduction}

Supracondylar humerus fractures are one of the major pediatric elbow fractures that account for 55 to $80 \%$ of all upper limb fractures. ${ }^{1}$ Most of these fractures occur as the result of a fall on an outstretched extremity. ${ }^{2}$ Falling onto an outstretched hand with a hyperextended elbow results in displacement of the distal portion of the humerus. ${ }^{3}$ The closeness of the vascular structures to the distal part of the humerus makes them susceptible to injury in case of a supracondylar humeral fracture. $^{4}$

The prevalence of vascular injury in pediatric patients with Gartland type-3 supracondylar humeral fractures has been reported in a range from $14 \%$ to $18.6 \%$ in different series. ${ }^{1,4,5}$ The mechanism of injury is associated with the mechanical displacement of the bone fragments over the neurovascular structures including the median nerve, radial nerve, and the brachial artery. ${ }^{6}$ The posterolateral displacement has seen $64 \%$ of the brachial artery injuries related to the supracondylar humerus fractures whereas the posteromedial displacement is seen in $36 \%$ of the cases. ${ }^{5}$ Vascular injury mechanism can either be an intimal damage or a total cut. Whatever the injury mechanism is, the vascular traumas have a high risk of morbidity associated with limb loss, and they require urgent management. ${ }^{6}$ In this paper, successful surgical management of a child with brachial artery injury related to a supracondylar humerus fracture is presented.

\footnotetext{
is Peer review under responsibility of The Society of Cardiovascular Academy.

* Corresponding author.

E-mail address: s_basbug@hotmail.com (H.S. Başbuğ).
}

\section{Case report}

A nine-year-old, otherwise healthy, right-hand-dominant boy was referred to the emergency department after he falls onto his left elbow. He described falling backward on a slippery surface while running and feeling immediate pain in the left elbow. On inspection, his humerus was immobile with a massive medial displacement. On physical examination, a closed supracondylar humerus fracture was determined. There was no hematoma or ecchymosis over the fracture region. The left antecubital brachial artery pulse, as well as the radial and ulnar pulses, was absent. The left hand was pale and cold that are indicative of poor perfusion. Neurological examination was normal with a normal motor and sensory function. Doppler ultrasound (DUS) examination revealed the cessation of brachial artery circulation at the level of the humeral fracture. Similarly, transverse slices of the Computerized Tomography (CT) angiography revealed an obstructed brachial artery image compatible with the site of dislocated humeral fracture line (Fig. 1).

The patient was taken to the operating room emergently by a team of orthopedics and cardiovascular surgery. Under general anesthesia, the humeral fracture was stabilized with percutaneous Kirschner wires following a closed reduction that was performed by the orthopedist. Despite the reduction, alignment, and fixation of the displaced fragments of the fractured humerus, distal pulses did not return. DUS examination revealed the same preoperative vascular signs without expected reflow. Traumatic brachial artery intimal injury was considered, and the surgical exploration of the brachial artery was performed. A discrete lesion of subintimal hematoma consistent with the arterial dissection was observed after the exploration of the brachial artery (Fig. 2). The injured arterial segment was resected (Fig. 3). Reconstructive anastomosis was performed in end-to-end fashion using 7-0 polypropylene suture (Fig. 4). Distal pulses returned soon after the release of vascular 


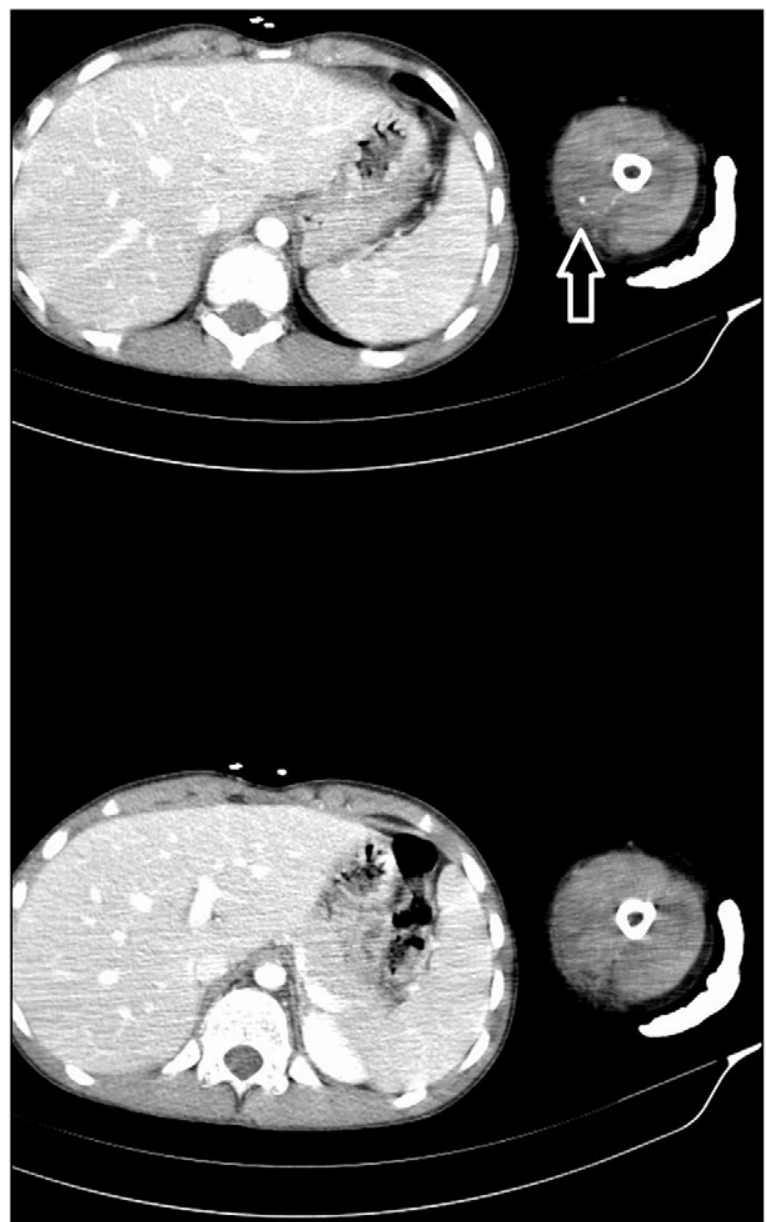

Fig. 1. Subsequent transverse slices of Computerized Tomography (CT) angiography revealed the cut brachial artery at the site of the humeral fracture line. Arrow is showing the brachial artery opacification.

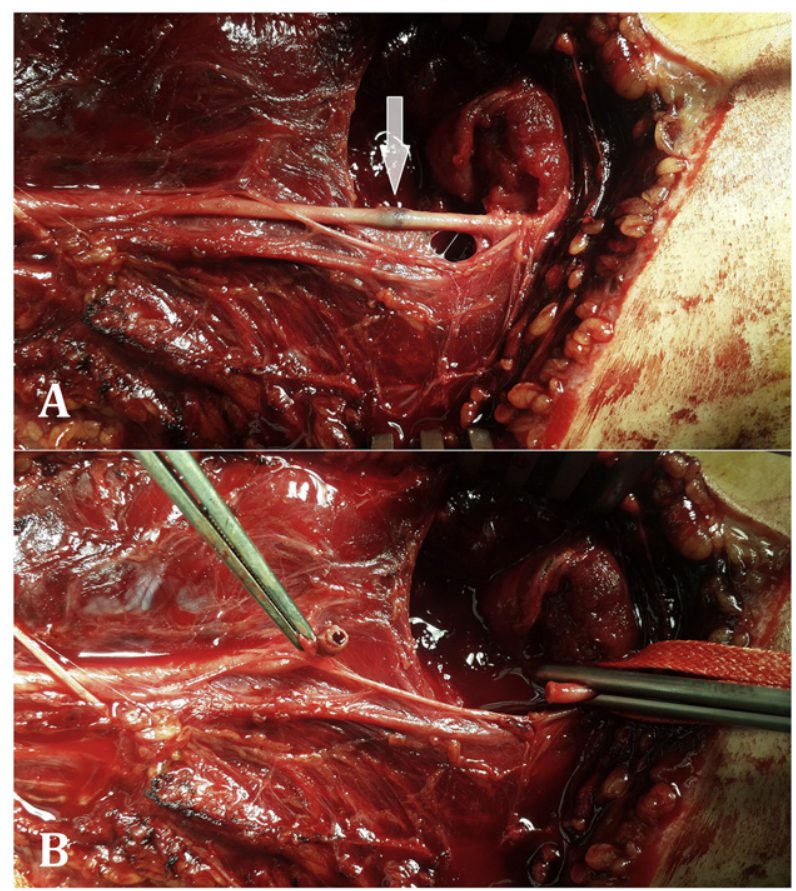

Fig. 2. (A) Brachial artery injury, the arrow indicates the injured segment with a subintimal hematoma. (B) Division of the injured part reveals a dissected brachial artery in which the intima and media layers were separated.

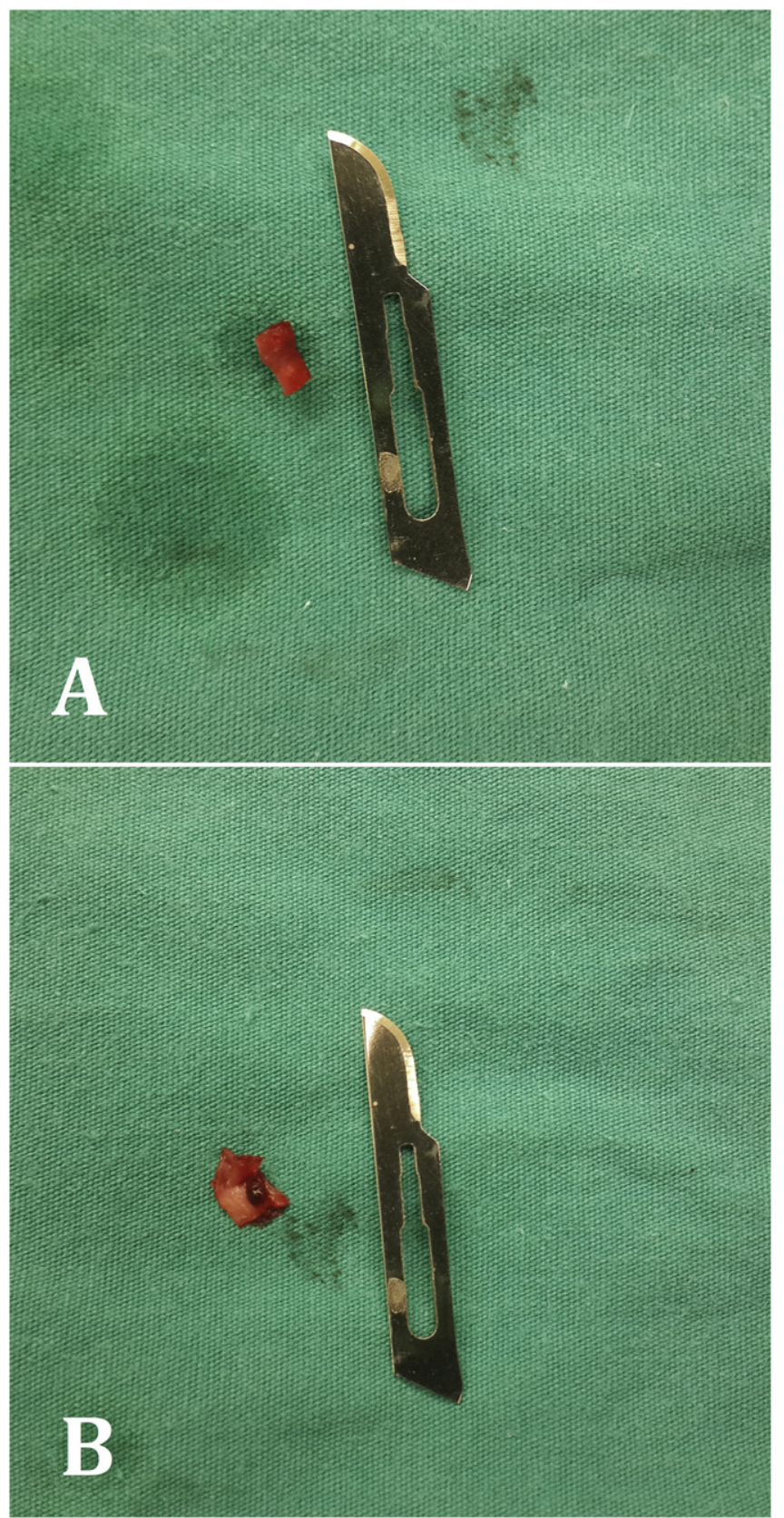

Fig. 3. (A) Macroscopic view of the resected brachial artery segment with an intimal injury. (B) Transsection of the injured segment reveals subintimal hematoma.

clamps. The patient was discharged fifth postoperative day with an arm-split and had no further complication.

\section{Discussion}

Pediatric supracondylar humerus fractures with a pulseless and poor-perfused hand should be operated emergently. If the limb still remains pulseless and ischemic after the surgical fracture fixation, vascular exploration, and repair (if needed) should be done. A pediatric supracondylar humerus fracture with a pulseless but well-perfused hand should be operated urgently. If the limb still remains pulseless after the surgical fracture fixation, vascular status should subsequently be reassessed. However, there are some controversies exist regarding the optimal management of this type of pediatric supracondylar humerus fractures with a pulseless but well-perfused hand. The opinions include an immediate vascular exploration or a twenty-four to forty- 


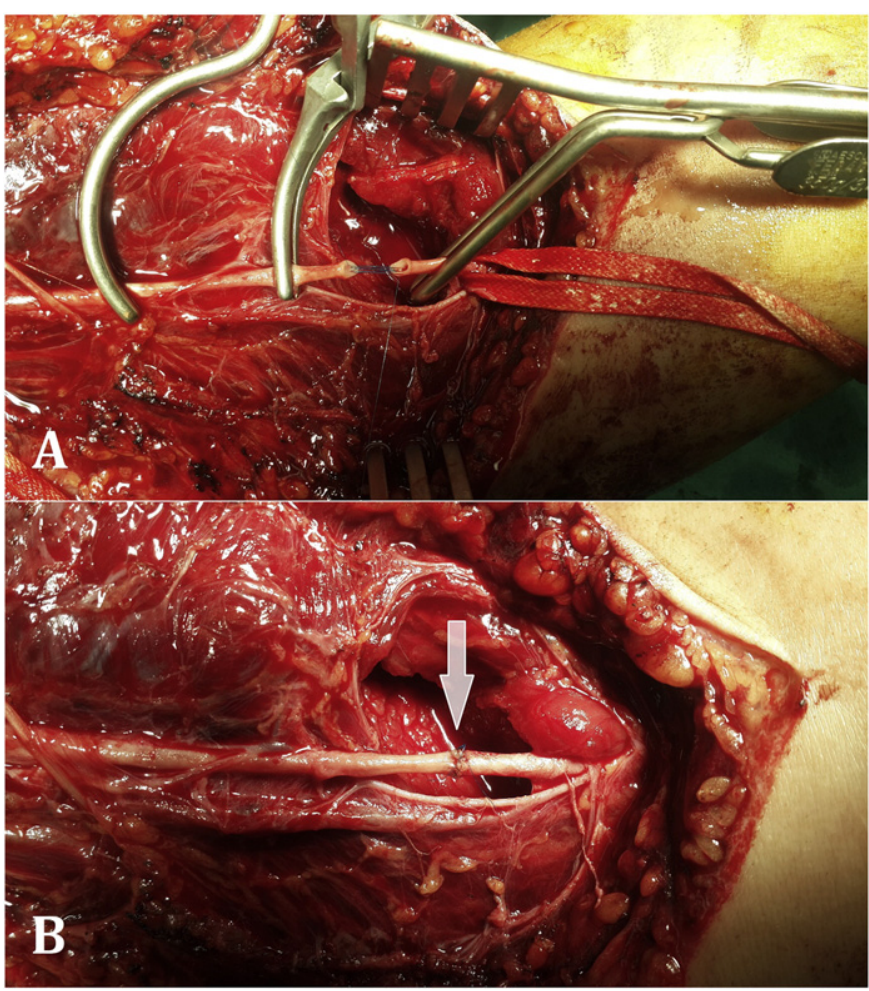

Fig. 4. (A) Reconstruction with end-to-end anastomosis of the clear edges. (B) The arrow shows the anastomotic line of the repaired brachial artery.

eight hour observation. The patient is returned to the operating room immediately for an emergent vascular management if perfusion of the hand is compromised during this period of observation. ${ }^{7}$ For patients whose palpable pulses do not return after reduction and fixation, many authors recommend surgical exploration if there is lack of a normal DUS signal. ${ }^{4}$

In this case, it was aimed to be emphasized that the vascular injury should always be considered after a supracondylar humerus fracture in children. Because displacement of the supracondylar humerus fractures in children often causes serious injuries to vascular structures of the affected limb. The brachial artery is mostly affected due to its intimacy with the humerus. Thus, pulseless and poorly perfused hands require emergent evaluation for the brachial artery injury in case of humeral fractures. Postponing the surgical intervention may cause permanent vascular dysfunction or even limb loss. Therefore, a prompt surgical management that is crucial for the limb protection should rapidly be constituted.

\section{Conflict of interest}

None declared.

\section{References}

1. Choi PD, Melikian R, Skaggs DL. Risk factors for vascular repair and compartment syndrome in the pulseless supracondylar humerus fracture in children. J Pediatr Orthop 2010;30:50-56.

2. Farnsworth CL, Silva PD, Mubarak SJ. Etiology of supracondylar humerus fractures. $J$ Pediatr Orthop 1998;18:38-42.

3. Cheng JCY, Lam TP, Maffulli N. Epidemiological features of supracondylar fractures of the humerus in Chinese children. J Pediatr Orthop B 2001;10:63-67.

4. Scannell BP, Brighton BK, VanderHave KL. Neurological and vascular complications associated with supracondylar humeral fractures in children. BIS Rev 2015;3:1-10.

5. Campbell CC, Waters PM, Emans JB, Kasser JR, Millis MB. Neurovascular injury and displacement in type III supracondylar humerus fractures. J Pediatr Orthop 1995;15: 47-52.

6. Shaw BA, Kasser JR, Emans JB, Rand FF. Management of vascular injuries in displaced supracondylar humerus fractures without arteriography. J Orthop Trauma 1990;4: 25-29.

7. Badkoobehi H, Choi PD, Bae DS, Skaggs DL. Management of the pulseless pediatric supracondylar humeral fracture. J Bone Joint Surg Am 2015;97:937-943. 